University of Wollongong

Research Online

Faculty of Engineering and Information

Faculty of Engineering and Information

Sciences - Papers: Part A

Sciences

$1-1-2013$

\title{
Advances in whole abdominal irradiation: What protons, VMAT, and IMRT using multicriteria optimization can offer
}

N Rochet

Massachusetts General Hospital,University of Heidelberg

E Batin

Massachusetts General Hospital

N Depauw

University of Wollongong, nd999@uowmail.edu.au

K Jee

Massachusetts General Hospital

H M. Kooy

Massachusetts General Hospital

See next page for additional authors

Follow this and additional works at: https://ro.uow.edu.au/eispapers

Part of the Engineering Commons, and the Science and Technology Studies Commons

Research Online is the open access institutional repository for the University of Wollongong. For further information contact the UOW Library: research-pubs@uow.edu.au 


\title{
Advances in whole abdominal irradiation: What protons, VMAT, and IMRT using multicriteria optimization can offer
}

\author{
Abstract \\ Abtract of paper presented 55th Annual Meeting of the American Society for Radiation Oncology 2013. \\ Keywords \\ abdominal, irradiation, advances, protons, whole, vmat, imrt, multicriteria, optimization, can, offer \\ Disciplines \\ Engineering | Science and Technology Studies

\section{Publication Details} \\ Rochet, N., Batin, E., Depauw, N., Jee, K., Kooy, H. M., Khan, F. hH., Paetzold, P. J., Russell, A. H., Bortfeld, T. \\ R. \& Craft, D. L. (2013). Advances in whole abdominal irradiation: What protons, VMAT, and IMRT using \\ multicriteria optimization can offer. International Journal of Radiation Oncology, 87 (2), S748-S749.

\section{Authors} \\ N Rochet, E Batin, N Depauw, K Jee, H M. Kooy, F H. Khan, P J. Paetzold, A H. Russell, T R. Bortfeld, and D \\ L. Craft
}




\section{6}

Advances in Whole Abdominal Irradiation: What Protons, VMAT, and IMRT Using Multicriteria Optimization Can Offer N. Rochet, ${ }^{1,2}$ E. Batin, ${ }^{1}$ N. Depauw, ${ }^{1,3}$ K. Jee, ${ }^{1}$ H.M. Kooy, ${ }^{1}$ F.H. Khan, ${ }^{1}$ P.J. Paetzold, ${ }^{1}$ A.H. Russell, ${ }^{1}$ T.R. Bortfeld, ${ }^{1}$ and D.L. Craft ${ }^{1}$;

${ }^{1}$ Massachusetts General Hospital - Harvard Medical School, Boston, MA ${ }^{2}$ University of Heidelberg - Department of Radiation Oncology, Heidelberg, Germany, ${ }^{3}$ University of Wollongong - Centre for Medical Radiation Physics, Wollongong, Australia

Purpose/Objective(s): The most commonly used technique for whole abdomen irradiation is an antero-posterior/postero-anterior (AP/PA) beam arrangement with liver and kidney blocking. Limitations include bone marrow toxicity which may impair or delay treatment, and underdosage to portions of the target volume (peritoneal cavity) due to liver and kidney shielding. The first aim of this study was to evaluate the potential of intensity-modulated radiation therapy (IMRT) and proton pencil-beam scanning (PBS) using multicriteria optimization (MCO) as well as volumetric modulated arc therapy (VMAT) to improve target coverage and sparing of organs at risk (OARs) compared to conventional AP/PA technique. The second aim was to discuss feasibility and availability of IMRT, VMAT and PBS in this indication.

Materials/Methods: IMRT, VMAT, PBS and new AP/PA plans were generated based on treatment planning CT scans of 10 patients previously treated with AP/PA technique. MCO was used for IMRT and PBS but was not available for VMAT. The planning target volume (PTV) included the entire peritoneal cavity, the liver capsule and the pelvic and para-aortic node regions. OARs were kidneys, liver, heart and bones. A total dose of 30 Gy was prescribed to the PTV in 20 fractions. Dose constraints were the same for all 4 treatment techniques and if all constraints could not be met, priority was given to the OARs over the target coverage. D95\% (PTV) and equivalent uniform doses (EUDs) were analyzed. Paired t-tests were used for statistical comparison.

Results: All 4 techniques met the constraints for OARs whereas only IMRT and PBS plans met the constraints for target coverage. In terms of coverage, IMRT, PBS and VMAT plans were all significantly superior to AP/PA plans with average D95\% of 29.1 Gy, 28.6 Gy, 25.1 Gy and 15.0 Gy, respectively. IMRT, VMAT and PBS achieved significantly better sparing of liver, heart and bones over AP/PA. The largest absolute dose difference was seen for bones, with average EUDs of 22.6 Gy for AP/PA versus 18.7 Gy (IMRT), 13.9 Gy (PBS) and 15.5 Gy (VMAT). Overall, PBS generated the best plans followed by IMRT and VMAT. Estimated average daily treatment time (beam on time only) was 5 min (AP/PA), 15 min (VMAT and PBS) and 40 min for IMRT, respectively.

Conclusions: IMRT, VMAT and PBS plans were all clearly superior to AP/ PA plans in terms of both target volume coverage and sparing of OARs, especially bones. Overall, PBS generated the best plan quality, but given the high costs, it is unclear if the dosimetric advantages are enough to justify its use for this indication. IMRT or VMAT should be offered to GYN patient population instead of AP/PA, VMAT being a good 
compromise in terms of daily treatment time. VMAT plan quality might be improved in the future with the implementation of multicriteria optimization.

Author Disclosure: N. Rochet: None. E. Batin: None. N. Depauw: None. K. Jee: None. H.M. Kooy: None. F.H. Khan: None. P.J. Paetzold: None. A.H. Russell: None. T.R. Bortfeld: E. Research Grant; RaySearch Laboratories, Stockholm, Sweden. D.L. Craft: E. Research Grant; RaySearch Laboratories, Stockholm, Sweden. 